\title{
Archeointensity study on baked clay samples taken from the reconstructed ancient kiln: implication for validity of the Tsunakawa-Shaw paleointensity method
}

\author{
Yuhji Yamamoto $^{1 *}$, Masayuki Torii ${ }^{2}$ and Nobuyoshi Natsuhara ${ }^{3}$
}

\begin{abstract}
In 1972, a reconstruction experiment of a kiln had been done to reproduce an excavated kiln of the seventh century in Japan. Baked clay samples were taken from the floor surface and $-20 \mathrm{~cm}$ level, and they have been stored after determinations of the paleomagnetic directions by partial alternating field demagnetizations. We recently applied the Tsunakawa-Shaw method to the samples to assess how reliable archeointensity results are obtained from the samples. A suite of the rock magnetic experiments and the scanning electron microscope observations elucidate that dominant magnetic carriers of the floor surface samples are Ti-poor titanomagnetite grains in approximately $10 \mathrm{~nm}$ size with single-domain and/or super-paramagnetic states, whereas contributions of multi-domain grains seem to be relatively large for the $-20-\mathrm{cm}$ level samples. From the floor surface samples, six out of the eight successful results were obtained and they give an average of $47.3 \mu \mathrm{T}$ with a standard deviation of $2.2 \mu \mathrm{T}$. This is fairly consistent with the in situ geomagnetic field of $46.4 \mu \mathrm{T}$ at the time of the reconstruction. They are obtained with a built-in anisotropy correction using anhysteretic remanent magnetization and without any cooling rate corrections. In contrast, only one out of four was successful from the $-20-\mathrm{cm}$ level samples. It yields an archeointensity of $31.6 \mu T$, which is inconsistent with the in situ geomagnetic field. Considering from the in situ temperature record during the firing of the kiln and the unblocking temperature spectra of the samples, the floor surface samples acquired full thermoremanent magnetizations (TRMs) as their natural remanent magnetizations whereas the $-20-\mathrm{cm}$ level samples only acquired partial TRMs, and these differences probably cause the difference in the archeointensity results between the two sample groups. For archeointensity researches, baked clay samples from a kiln floor are considered to be ideal materials.
\end{abstract}

Keywords: Archeointensity; Absolute paleointensity; Baked clay; Kiln; Tsunakawa-Shaw method

\section{Background}

Recent advances in archeomagnetism have resulted in sophisticated databases for published archeomagnetic data. For example, the GEOMAGIA50 database (Donadini et al. 2006; Korhonen et al. 2008) involves about 8,000 geomagnetic field directions and intensities for the past 50 kyr. The ARCH3k database by Donadini et al. (2009) contains 2,671 declination, 4,174 inclination, and 2,670 intensity data from archeological artifacts and lavas for the past

\footnotetext{
* Correspondence: y.yamamoto@kochi-u.ac.jp

${ }^{1}$ Center for Advanced Marine Core Research, Kochi University, B200 Monobe, Nankoku, Kochi 783-8502, Japan

Full list of author information is available at the end of the article
}

3 kyr. Genevey et al. (2008) compiled the Archeoint database for the past $10 \mathrm{kyr}$ which has 3,648 archeointensity records reported from archeological artifacts and lavas.

Concerning the Archeoint database, $70 \%$ of the records are from Europe while only 12\% of them are from East Asia. Among the East Asia records, 188 data are from Japan: 145 data from archeological artifacts (9 data, Nagata and Arai (1963); 19 data, Sasajima and Maenaka (1966); 56 data, Kitazawa (1970); 6 data, Domen (1977); 58 data, Sakai and Hirooka (1986)) and 43 data from lavas (7 data, Nagata and Arai (1963); 2 data, Sasajima and Maenaka (1966); 6 data, Kono (1978); 1 data, Tanaka (1979); 13 data, Tanaka (1980); 3 data, Tsunakawa and 
Shaw (1994); 1 data, Takai et al. (2002); 10 data, Yoshihara et al. (2003)).

In broad sense, 'archeointensity' stands for an absolute paleointensity of the geomagnetic field during historical period which is estimated from both archeological artifacts and lavas. In narrow sense, the estimation material is limited to archeological artifacts. Generally speaking, archeological artifacts have been considered to be more reliable paleointensity recorders, because they were certainly burned/baked by our ancestors and their natural remanent magnetizations (NRMs) are definitely thermoremanent magnetization (TRM) origin with good thermal stability.

There has been a long gap in time since the last internationally recognized archeointensity result was published from archeological artifacts in Japan (e.g., Sakai and Hirooka 1986). In contrast, brand new data with modern paleointensity techniques have been published from East Asia outside Japan, for example, Korea (Yu et al. 2010; Hong et al. 2013) and China (Cai et al. 2014). In 1960s to 1970s, a group of Japanese researchers had made systematic oriented-sample collections from baked clay at many pottery kilns excavated in and around Sakai city, Osaka prefecture, Japan. The collections were associated with a lot of excavations arising from a big demand of housing land developments due to the growing economy in Japan at that time. Paleomagnetic directions for fifth to tenth centuries were intensively measured from these samples, and they were published by Hirooka (1971) and Shibuya (1980). Untreated and/or partially demagnetized samples have been reserved and stored for further archeointensity (paleointensity) researches.

A relatively large number of the reserved samples were partially demagnetized by alternating field (AF) up to 20 to $40 \mathrm{mT}$. Thus, AF-based paleointensity techniques are thought to be suitable for these samples. The Tsunakawa-Shaw method, which has been previously called the LTD-DHT Shaw method (Tsunakawa and Shaw 1994; Yamamoto et al. 2003), is one of such techniques. Its applicability and validity have been elucidated for various types of volcanic rocks from historical lava flows (e.g., Yamamoto et al. 2003; Mochizuki et al. 2004; Oishi et al. 2005; Yamamoto and Hoshi 2008) but remain unassessed for archeological artifacts including baked clay.

In the vicinity of the archeological sites, Nakajima et al. (1974) conducted a reconstruction experiment: they reconstructed a kiln which was carefully imitating an excavated kiln of the seventh century and measured paleomagnetic directions from baked clay samples taken from the kiln. These samples have been reserved and stored after partial AF demagnetization by 20 to $40 \mathrm{mT}$ in 1972. In the present study, we applied the TsunakawaShaw method to these samples. Because the reconstruction experiment was done after the measurement of the in situ geomagnetic field, we can compare the in situ filed with archeointensity results obtained by the TsunakawaShaw method. We also conducted a suite of rock magnetic experiments and an observation with scanning electron microscope, to characterize rock magnetic properties of the samples.

\section{Reconstruction experiment}

The reconstruction experiment was conducted in Sakai city, Osaka, Japan, on January 1972 (Nakajima et al. 1974). A Noborigama kiln, which was carefully imitating an excavated one of the seventh century, was reconstructed and fired with many Sue-type earthenwares in it (Figure 1).

After cutting the trees and weeds (Figure 1a), the ground was dug up (Figure 1b). Then in situ geomagnetic field was measured by a Schmidt-type magnetometer (Figure 1c): declination $(\mathrm{Dec})=-5.63^{\circ}$, inclination $(\mathrm{Inc})=$ $46.78^{\circ}$, and intensity (Int) $=46.350 \mu \mathrm{T}$. This is fairly consistent with the field calculated from the model of IGRF-11 (IAGA Division V, Working Group V-MOD 2010) at the place for the year of 1972: Dec $=-6.23^{\circ}$, Inc $=47.7^{\circ}$, and Int $=46.438 \mu \mathrm{T}$. To record in situ temperature variations during the firing, thermocouples were embedded in and around the kiln (Figure 1d,e). After the embedment, the body of the kiln was made up with bamboos and tree branches, and they were subsequently covered and coated with clay (Figure 1f). With Sue-type earthenwares, the firing was done using naturally grown pine trees and other miscellaneous woods taken around the kiln (Figure 1g,h).

It was found that the temperature very close to the floor surface ( -2 -cm level, three different positions) was risen up to approximately $1,000^{\circ} \mathrm{C}$ while that at the level $20 \mathrm{~cm}$ below the floor $(-20-\mathrm{cm}$ level $)$ was only up to approximately $350^{\circ} \mathrm{C}$ during firing (Figure 2). After reaching to the highest temperature of approximately $1,000^{\circ} \mathrm{C}$, the fire hole and the chimney of the kiln were blocked to make the inside reductive atmosphere. The kiln was then naturally cooled down for approximately $24 \mathrm{~h}$. After the cooling down (Figure 1i,j), baked clay was carefully sampled from the floor surface (Figure 1k) and the $-20-\mathrm{cm}$ level (Figure 1l) using plaster of Paris for accurate orientation. Each sample was cut in laboratory into cubic shape with approximately $3.7 \mathrm{~cm}$ on a side.

The samples were subjected to partial AF demagnetization up to 20 to $40 \mathrm{mT}$. Nakajima et al. (1974) reported that the mean paleomagnetic directions resulted in Dec $=-5.03^{\circ}$, Inc $=43.37^{\circ}$, and $\alpha_{95}=2.42^{\circ}$ for the floor surface samples $(N=10)$ and in Dec $=-4.80^{\circ}$, Inc $=43.52^{\circ}$, and $\alpha_{95}=3.38^{\circ}$ for the $-20-\mathrm{cm}$ level samples $(N=5)$. These directions were reasonably consistent with the in situ geomagnetic field direction measured prior to the firing, though the mean inclinations were approximately $3^{\circ}$ shallower than the in situ field. 

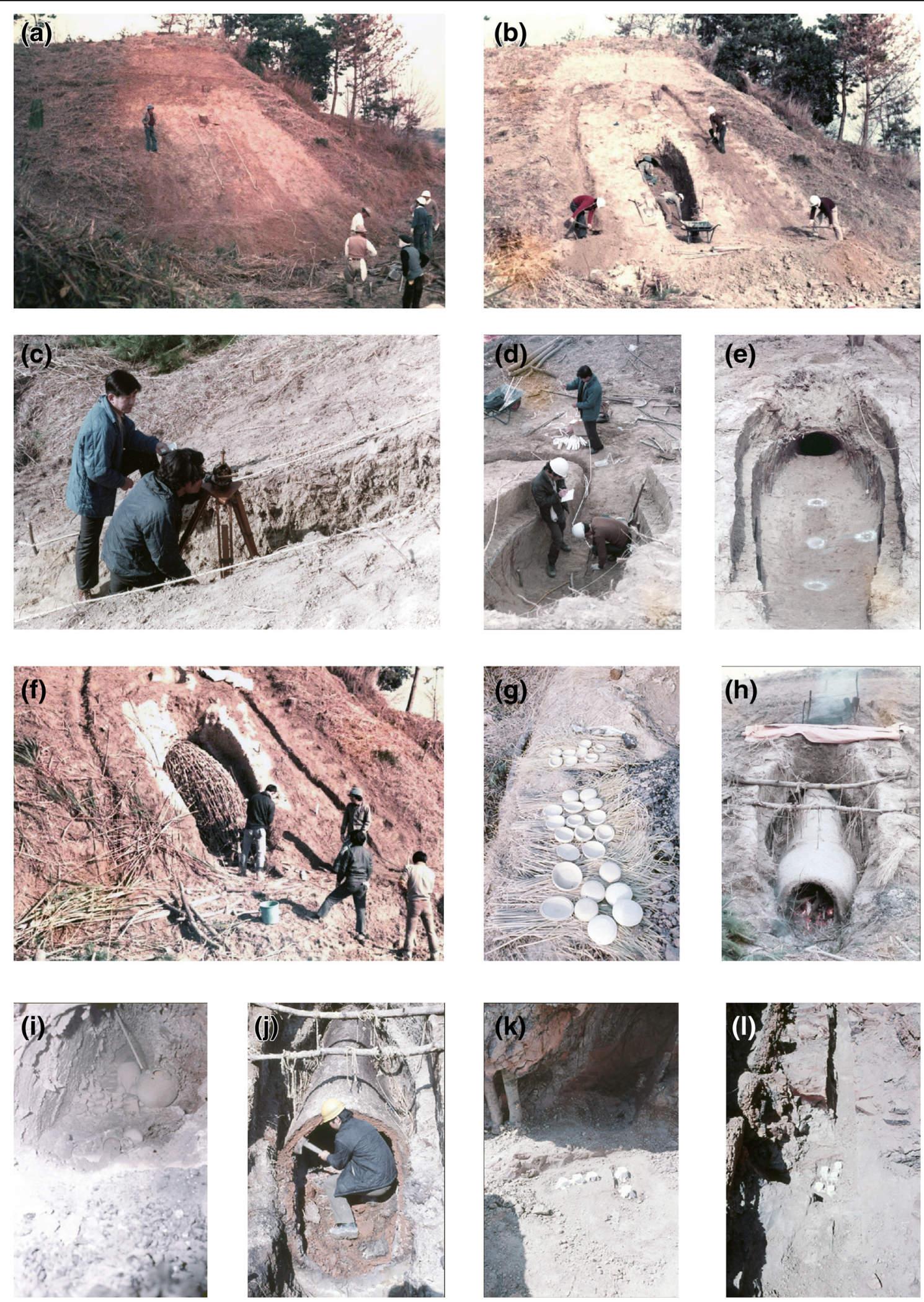

Figure 1 (See legend on next page.) 
(See figure on previous page.)

Figure 1 A series of the photographs taken during the reconstruction experiment by Nakajima et al. (1974). (a) Local trees and weeds were trimmed to reconstruct a Noborigama kiln. (b) Ground was dug up. (c) In situ geomagnetic field was measured by a Schmidt-type magnetometer. (d) Thermocouples were embedded in and around the kiln to record in situ temperature variations during firing. (e) White circles indicate example locations of the thermocouple contacts. (f) A body of the kiln was made up with bamboos and tree branches, which were subsequently covered and coated with clay. (g) Sue-type earthenwares to be fired. (h) Firing was done using naturally grown pine trees and other miscellaneous woods taken around the kiln. The bamboos and tree branches were gutted by fire, and baked clay remained as the kiln body. (i) Inside view of the kiln after firing. (j) Cross-section of the fire hole after firing. (k, I) Baked clay was carefully sampled from the floor surface (k) and the -20-cm level (I) using plaster with orientation.

\section{Methods}

\section{Samples}

The cubic samples had been stored for approximately 40 years in an ambient field after the partial AF demagnetization. In the present study, eight samples from the floor surface (numbered 1, 2, 5, 8, 9, 11, 12, and 13) and four samples from the $-20-\mathrm{cm}$ level (numbered 15, 16, 18, and 19) were prepared for the experiments. They were cut vertical to horizontal planes into two pieces, one of which was reserved as an archive while the other was further cut into several mini specimens for paleointensity and rock magnetic experiments (Figure 3a). The floor surface samples are all reddish (Figure $3 \mathrm{~b}$ ) whereas the $-20-\mathrm{cm}$ level ones are all grayish (Figure 3c).

\section{Rock magnetic experiments}

The hysteresis parameters, saturation magnetization $\left(M_{\mathrm{s}}\right)$, saturation remanent magnetization $\left(M_{\mathrm{rs}}\right)$, coercive force $\left(B_{\mathrm{c}}\right)$, and coercivity of remanence $\left(B_{\mathrm{rc}}\right)$ were measured for two to four chips from each sample, using a

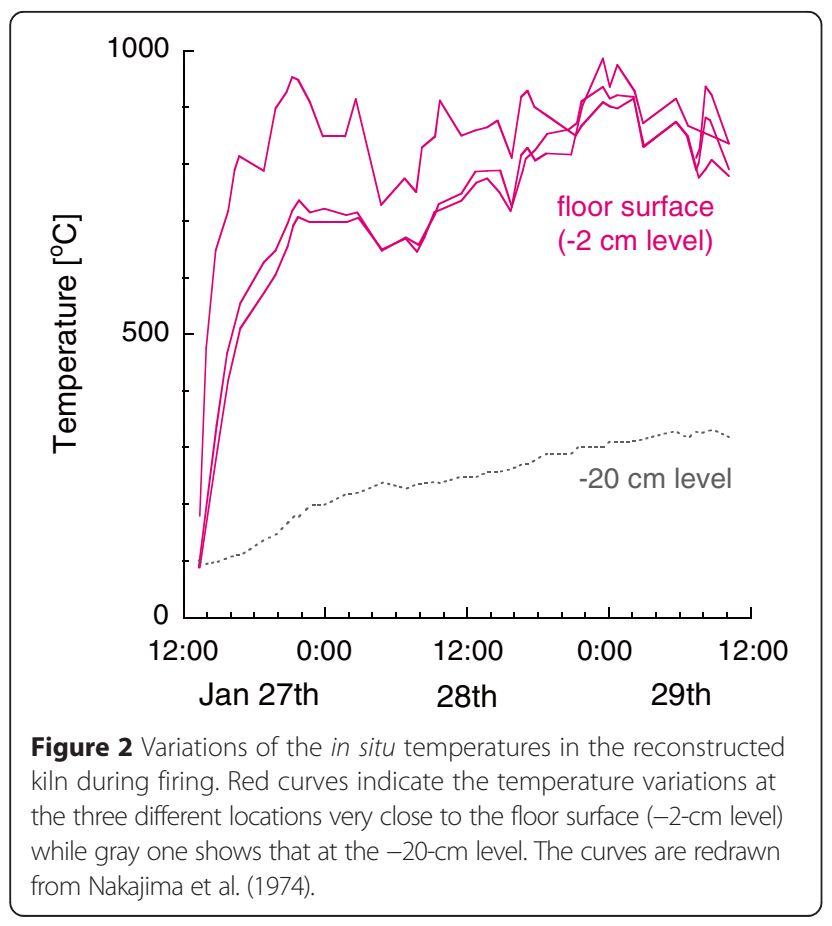

vibrating sample magnetometer (MicroMag 3900 VSM, Princeton Measurements Corporation, Princeton, NJ, USA). Thermomagnetic curve measurements were performed in vacuum (approximately 1 to $10 \mathrm{~Pa}$ ) on chip samples from most of the samples using a magnetic balance (NMB-89, Natsuhara Giken, Osaka, Japan). In the measurements, chip samples were gradually heated from approximately $30^{\circ} \mathrm{C}$ to $700^{\circ} \mathrm{C}$ and then gently cooled to approximately $50^{\circ} \mathrm{C}$, with the rate of $10^{\circ} \mathrm{C} / \mathrm{min}$. Throughout the temperature cycle, a field of $500 \mathrm{mT}$ was kept applied to the sample.

To obtain unblocking temperature $\left(\mathrm{T}_{\mathrm{UB}}\right)$ spectra data for NRMs and isothermal remanent magnetizations (IRMs) both from the floor surface and the $-20-\mathrm{cm}$ level samples, each of two mini specimens from the samples 5 and 16 is subjected to thermal demagnetization (ThD) experiments. Because NRMs of the two samples were already demagnetized by AF of $20 \mathrm{mT}$ in Nakajima et al. (1974), for a one set of the specimens, IRMs of $2.5 \mathrm{~T}$ were imparted by a pulse magnetizer (MMPM10, Magnetic Measurements, Lancashire, UK) and subsequently demagnetized at $20 \mathrm{mT}$ using an AF demagnetizer (DEM-95, Natsuhara Giken). Stepwise ThD was then conducted on NRMs and IRMs of the mini specimens at $30^{\circ} \mathrm{C}$ to $50^{\circ} \mathrm{C}$ steps up to $600^{\circ} \mathrm{C}$ using a thermal demagnetizer (TDS-1, Natsuhara Giken). Remanent magnetizations were measured by a spinner magnetometer (ASPIN-A, Natsuhara Giken).

\section{Scanning electron microscope (SEM) observation}

Sliced pieces from the samples 5 and 16 were impregnated with epoxy and subsequently polished to mirror gloss. The polished surface of the pieces was then thin-coated with platinum and they were observed by a field emission scanning electron microscope (FE-SEM, JSM-6500F, JEOL Ltd., Akishimashi, Tokyo, Japan). We took backscattered electron images (BEIs) and made point analyses based on an energy-dispersive X-ray spectroscopy (EDS). Spatial resolution was as good as 10 to $100 \mathrm{~nm}$ in a BEI whereas it was a few micrometers at best for an EDS point analysis.

\section{Tsunakawa-Shaw paleointensity experiments}

The Tsunakawa-Shaw method (Tsunakawa and Shaw 1994; Yamamoto et al. 2003) was applied to mini specimens from 


\section{(a) sample 1, floor surface}

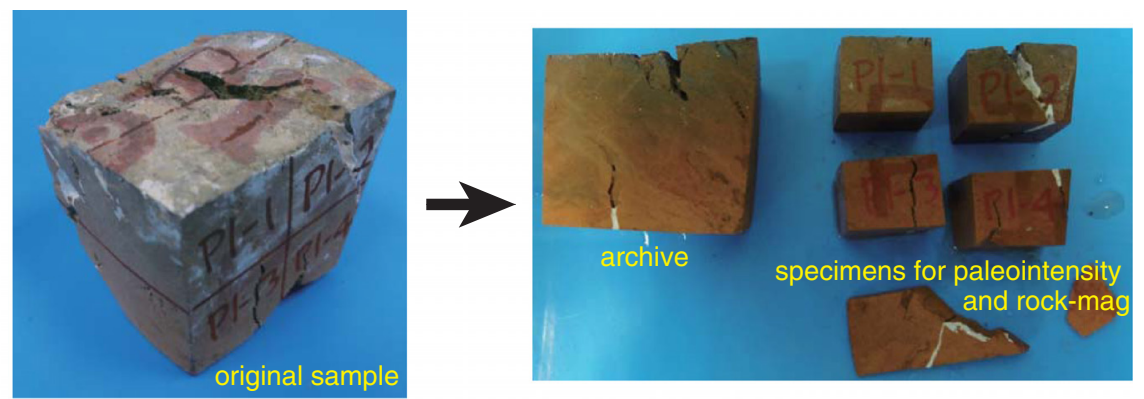

(b) sample 5, floor surface

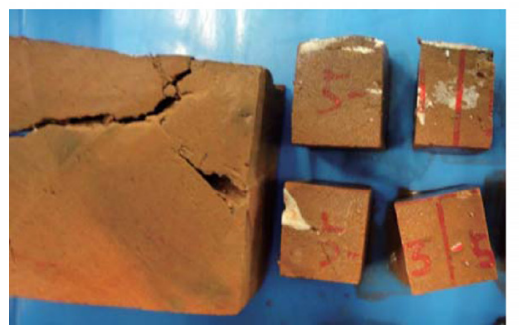

(c) sample 16, $-20 \mathrm{~cm}$ level

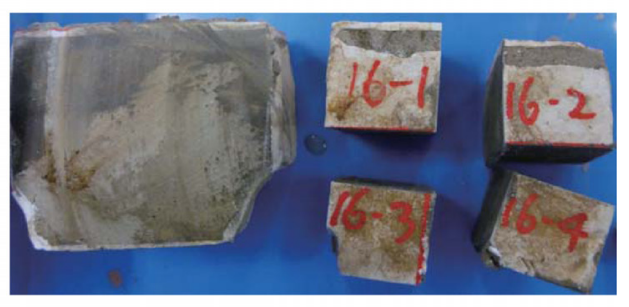

Figure 3 Photographs showing the samples used for archeointensity (paleointensity) and rock magnetic experiments. (a) An original cube sample (approximately $3.7 \mathrm{~cm}$ on a side) is vertically cut into two pieces. One is reserved as an archive while the other is further cut into several mini specimens for archeointensity (paleointensity) and rock magnetic experiments. Example photographs are shown for sample 1 from the floor surface. (b) An example photograph for sample 5 from the floor surface. (c) An example photograph for sample 16 from the -20-cm level.

all the samples to determine archeointensities (absolute paleointensities). This method estimates archeointensities based on coercivity spectra rather than blocking temperature spectra. Detailed procedures are described in Yamamoto and Tsunakawa (2005).

Main procedures in the present study are as follows:

i. A specimen undergoes low-temperature demagnetization (LTD; Ozima et al. 1964). NRM after LTD is subjected to stepwise AF demagnetization. The remanence is measured at each step [NRM].

ii. Anhysteretic remanent magnetization (ARM) is imparted to the specimen. Then, the specimen undergoes LTD. ARM after LTD is subjected to stepwise AF demagnetization and is measured at each step [ARM0].

iii. The specimen is heated in a furnace to impart full TRM for the first time. Then, the same procedures as (i) and (ii) are performed for the TRM [TRM1] and ARM [ARM1].

iv. The specimen is heated in the furnace to impart TRM for the second time. The same procedures as (i) and (ii) are performed for the TRM [TRM2] and ARM [ARM2].
For the remanent magnetization measurements, stepwise AF demagnetizations, and the impartment of ARMs, we used an automated spinner magnetometer with an AF demagnetizer (DSPIN, Natsuhara Giken). The demagnetizations were conducted up to $180 \mathrm{mT}$, with the steps at 2-mT intervals up to $30 \mathrm{mT}$, at $5-\mathrm{mT}$ intervals up to $100 \mathrm{mT}$, and 10-mT intervals up to 180 mT. ARMs were imparted using a DC bias field of 50 $\mu \mathrm{T}$ with a peak AF of $180 \mathrm{mT}$, by setting the bias field direction approximately parallel to the NRM and laboratory TRM directions. LTD was conducted such that specimens were soaked in liquid nitrogen for $10 \mathrm{~min}$ and subsequently left at room temperature for $30 \mathrm{~min}$ in a zero field. For the impartment of TRMs, we used a thermal demagnetizer equipped with a DC field coil (TDS-1, Natsuhara Giken). The specimens were heated to $610^{\circ} \mathrm{C}$ in a vacuum ( 1 to $10 \mathrm{~Pa}$ ) with the hold time of 10 (TRM1) and 20 (TRM2) $\mathrm{min}$ at that temperature and subsequently cooled down to room temperature for approximately $2 \mathrm{~h}$ in a $40-\mu \mathrm{T}$ DC field throughout this process.

Obtained results were analyzed based on NRM-TRM1* and TRM1-TRM2* diagrams. TRM1* and TRM2* denote the TRM imparted in the first (TRM1) and second 
(TRM2) heating, as corrected using the technique of Rolph and Shaw (1985):

$$
\begin{aligned}
& \text { TRM1 } *=\text { TRM1 } \times(\text { ARM0/ARM1 }) \\
& \text { TRM2 } *=\text { TRM2 } \times(\text { ARM1 } / \text { ARM2 })
\end{aligned}
$$

The slope from the NRM-TRM1* diagram was used to calculate the archeointensity, while that from the TRM1-TRM2* diagram was to check the validity of the ARM correction. We adopted the following selection criteria, which are similar to those used in recent paleointensity studies with the Tsunakawa-Shaw method (e.g., Yamamoto et al. 2010; Mochizuki et al. 2013; Yamazaki and Yamamoto 2014).

(1) A primary component is resolved from NRM by stepwise AF demagnetization.

(2) A single linear segment is recognized in the NRMTRM1* diagram within the coercivity range of the primary NRM component. The segment spans at least $30 \%$ of the total extrapolated NRM $\left(f_{N} \geq 0.30\right.$; definition of the extrapolation is the same as in Coe et al. (1978)). The correlation coefficient of the segment is not smaller than $0.995\left(r_{N}>=0.995\right)$.

(3) A single linear segment $\left(f_{T} \geq 0.30\right.$ and $\left.r_{T} \geq 0.995\right)$ is also recognized in the TRM1-TRM2* diagram. The slope of the segment is unity within experimental errors $(1.05 \geq \operatorname{slope} T \geq 0.95)$ as proof of the validity of the ARM correction.

For approximate estimations of remanence anisotropies of the samples, ARMs were imparted on unheated sister specimens with two different directions and those after LTD were measured. One direction was approximately parallel to the NRM direction ( $\mathrm{ARM}_{\mathrm{NRM}}$ direction), and the other direction was to the laboratory TRM direction $\left(\mathrm{ARM}_{\mathrm{TRM} \text { direction }}\right)$. Conditions of the impartments were same as those in the main experiment.

\section{Results}

\section{Rock magnetic experiments}

Sample-averaged ratios of $B_{\mathrm{rc}} / B_{\mathrm{c}}$ and $M_{\mathrm{rs}} / M_{\mathrm{s}}$ are listed in Table 1 and shown in Figure 4 on a Day plot (Day et al. 1977; Dunlop 2002). Data points in the Day plot are distributed between the single-domain to multidomain (SD-MD) and SD to super-paramagnetic (SDSP) mixing curves for magnetites by Dunlop (2002). The points originated from the floor surface samples (red triangles) tend to lie closer to the $\mathrm{SD}$ region than those from the -20 -cm level samples (gray circles). This tendency is clearly recognized when we consider ground means of the former and latter samples (red and gray squares). It is thought that dominant magnetic carriers are SD and/or SP grains for the floor surface samples while contributions of MD grains seem to be relatively large for the $-20-\mathrm{cm}$ level samples.

Thermomagnetic curves show two Curie temperature phases at approximately $250^{\circ} \mathrm{C}$ and approximately $550^{\circ} \mathrm{C}$ in heating, and the former phase is disappeared in cooling (Figure 5). In spite of the disappearance, the curves are generally reversible. This suggests that thermal stability in laboratory heating, one of the key factors in absolute paleointensity experiments, is reasonably good. Some prominent characters in the curves are that (1) the curves from $-20-\mathrm{cm}$ level samples are obviously noisier than those from floor surface samples and that (2) the phase at approximately $250^{\circ} \mathrm{C}$ on heating is more prominent in the curves from $-20-\mathrm{cm}$ level samples. These characters seem to be originated from possible less formation of Ti-poor titanomagnetites due to the insufficient baking of the -20$\mathrm{cm}$ level samples during firing of the reconstructed kiln. In actual, laboratory-imparted ARMs of the $-20-\mathrm{cm}$ level samples resulted in the intensities one order of magnitude smaller than those of the floor surface samples (Table 1).

Results of the ThD experiments are shown in Figure 6. They show that unblocking behaviors of IRMs are different between the samples 5 and 16 particularly for the temperature range above $200^{\circ} \mathrm{C}$ : major unblocking occurs at higher temperature in the sample 5 than in the sample 16. This is probably because of less formation of magnetic grains in the $-20-\mathrm{cm}$ level samples due to the insufficient baking as discussed in above. The results also exhibit that unblocking behaviors are similar between NRM and IRM for sample 5 (Figure 6a) while they are different for sample 16 (Figure 6b) as evidenced from NRM/IRM ratios: the ratio is generally constant at approximately 0.02 throughout the temperature range for the sample 5 (Figure 6a) whereas it shows a systematic increase at higher temperature for sample 16 (Figure 6b). This implies that NRM of sample 5 resulted in acquisition of full TRM during firing of the reconstructed kiln while that of sample 16 only in acquisition of partial TRM, assuming that IRM has a similar unblocking behavior with full TRM.

\section{Scanning electron microscope (SEM) observation}

Representative BEIs are shown in Figure 7 with results of the EDS point analyses. In both the samples from floor surface (sample 5) and $-20-\mathrm{cm}$ level (sample 16), Fe-Ti oxide minerals are present. It is clearly recognized that the minerals in approximately $10 \mathrm{~nm}$ size are abundant in the floor surface sample (sample 5) while those in approximately 1 to $10 \mu \mathrm{m}$ size are dispersed in the $-20-\mathrm{cm}$ level samples. These observations are consistent with the results 
Table 1 Results of the rock magnetic experiments and the Tsunakawa-Shaw paleointensity experiments

\begin{tabular}{|c|c|c|c|c|c|c|c|c|c|c|c|c|c|c|c|c|c|c|}
\hline \multirow[t]{2}{*}{ Sample } & \multirow{2}{*}{$\begin{array}{l}\mathrm{ARMO}_{0} \\
{\left[10^{-5} \mathrm{Am}^{2} / \mathrm{kg}\right]}\end{array}$} & \multirow[t]{2}{*}{$N_{\text {hys }}$} & \multirow[t]{2}{*}{$\mathrm{B}_{\mathrm{rc}} / \mathrm{B}_{\mathrm{c}}$} & \multirow[t]{2}{*}{$M_{r s} / M_{s}$} & \multirow{2}{*}{$\begin{array}{l}\text { LTD } \\
\text { [\%] }\end{array}$} & \multirow{2}{*}{$\begin{array}{l}\text { Anisotropy } \\
\text { ratio }\end{array}$} & \multicolumn{5}{|c|}{ First heating } & \multicolumn{5}{|c|}{ Second heating } & \multirow{2}{*}{$\begin{array}{l}F \\
(\mu T)\end{array}$} & \multirow[t]{2}{*}{$\triangle \mathrm{AIC}$} \\
\hline & & & & & & & $\mathrm{H}_{\mathrm{c}}$ & Slope $_{\mathrm{A} 1}$ & Slope $_{N}$ & $f_{N}$ & $r_{N}$ & $\mathrm{H}_{\mathrm{c}}$ & Slope $_{\mathrm{A} 2}$ & Slope $_{T}$ & $f_{T}$ & $r_{T}$ & & \\
\hline \multicolumn{19}{|c|}{ Floor surface } \\
\hline 1 & 247 & 2 & 1.564 & 0.4267 & 21.8 & 1.12 & $40-180$ & 0.882 & 1.28 & $(0.166)$ & $(0.982)$ & $0-180$ & 1.03 & $(1.05)$ & 0.999 & 1.00 & & -1.66 \\
\hline 2 & 343 & 2 & 2.730 & 0.2696 & 9.1 & 0.972 & $40-110$ & 0.932 & 1.08 & 0.369 & 1.00 & $0-180$ & 1.02 & 0.978 & 0.986 & 0.999 & 43.2 & 0.17 \\
\hline 5 & 302 & 2 & 1.470 & 0.4252 & 24.7 & 1.05 & $20-180$ & 0.976 & 1.16 & 0.570 & 0.999 & $0-180$ & 1.00 & 1.05 & 1.01 & 1.00 & 46.4 & 5.26 \\
\hline 8 & 274 & 4 & 1.581 & 0.3970 & 16.5 & 1.03 & $20-180$ & 0.991 & 1.20 & 0.530 & 0.999 & $14-180$ & 1.03 & 1.05 & 0.779 & 0.999 & 48.0 & -0.17 \\
\hline 9 & 171 & 2 & 1.702 & 0.4296 & 32.9 & 1.06 & $20-180$ & 0.939 & 1.21 & 0.691 & 0.999 & $0-180$ & 1.04 & 0.984 & 0.998 & 1.00 & 48.4 & 11.6 \\
\hline 11 & 261 & 4 & 2.029 & 0.3420 & 14.0 & 0.980 & $20-180$ & 0.972 & 1.24 & 0.672 & 0.998 & $0-180$ & 0.969 & 1.04 & 1.01 & 0.999 & 49.6 & 16.3 \\
\hline 12 & 142 & 4 & 1.683 & 0.4074 & 24.2 & 1.24 & $20-180$ & 1.04 & 1.20 & 0.503 & 0.999 & $0-180$ & 1.01 & 1.02 & 0.999 & 1.00 & 48.0 & 0.18 \\
\hline \multirow[t]{3}{*}{13} & 262 & 4 & 1.750 & 0.4001 & 28.5 & 1.10 & $45-180$ & 0.925 & 0.994 & $(0.233)$ & 0.998 & $0-180$ & 1.00 & 1.05 & 0.993 & 1.00 & & 11.9 \\
\hline & 250 & 8 & 1.814 & 0.3872 & 21.4 & & & & & & & & & & & & 47.3 & \\
\hline & \pm 66 & & \pm 0.406 & \pm 0.0552 & \pm 7.9 & & & & & & & & & & & & \pm 2.2 & \\
\hline \multicolumn{19}{|c|}{$-20-\mathrm{cm}$ level } \\
\hline 15 & 38.2 & 2 & 2.153 & 0.3064 & 7.8 & 1.06 & $70-180$ & 0.826 & 1.46 & $(0.206)$ & 0.995 & $0-180$ & 1.08 & 0.984 & 1.01 & 1.00 & & 0.55 \\
\hline 16 & 21.0 & 2 & 2.385 & 0.2372 & 4.0 & 0.986 & $20-120$ & 1.01 & 0.790 & 0.743 & 0.996 & $0-180$ & 1.08 & 0.999 & 0.977 & 0.998 & 31.6 & -0.31 \\
\hline 18 & 3.69 & 2 & 3.639 & 0.1344 & 20.5 & 0.941 & $20-180$ & 1.03 & 0.909 & 0.623 & $(0.964)$ & $0-180$ & 0.939 & 1.01 & 0.914 & 0.968 & & -0.92 \\
\hline \multirow[t]{3}{*}{19} & 5.35 & 2 & 4.905 & 0.1164 & 7.5 & 0.958 & $20-180$ & 1.00 & 0.863 & 0.547 & $(0.883)$ & $0-180$ & 0.934 & 0.985 & 0.970 & 0.986 & & 7.79 \\
\hline & 17.1 & 4 & 3.271 & 0.1986 & 10.0 & & & & & & & & & & & & 31.6 & \\
\hline & \pm 16.1 & & \pm 1.270 & \pm 0.0894 & \pm 7.2 & & & & & & & & & & & & & \\
\hline
\end{tabular}

$\mathrm{ARMO}_{0}$, initial ARM0 intensity after LTD; $N_{\text {hys }}$ number of chips for the hysteresis measurements; $B_{r c} / B_{c}, M_{r s} / M_{s}$ sample-averaged ratios of coercivity of remanence $\left(B_{r c}\right)$ to coercive force $\left(B_{c}\right)$ and saturation remanent magnetization $\left(M_{r s}\right)$ to saturation magnetization $\left(M_{s}\right)$; LTD, LT demagnetized fraction of ARMO; anisotropy ratio, ratios of $A R M_{T R M}$ direction to $A R M_{N R M}$ direction before laboratory heating; $H_{C}$, the coercivity interval taken for

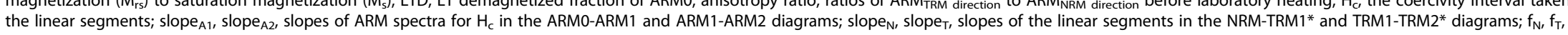
NRM and TRM1 fractions of the linear NRM-TRM1* and TRM1-TRM2* segments; $r_{N}, r_{T}$, correlation coefficients of the linear NRM-TRM1* and TRM1-TRM2* segments; $F$, calculated paleointensity; $\triangle A$ AIC, AIC difference between linear and quadratic fit (Yamamoto and Tsunakawa, 2005); Numbers in parentheses indicate out of the selection criteria; Numbers in italic are averaged values with their $1 \sigma$ for the sample groups. 


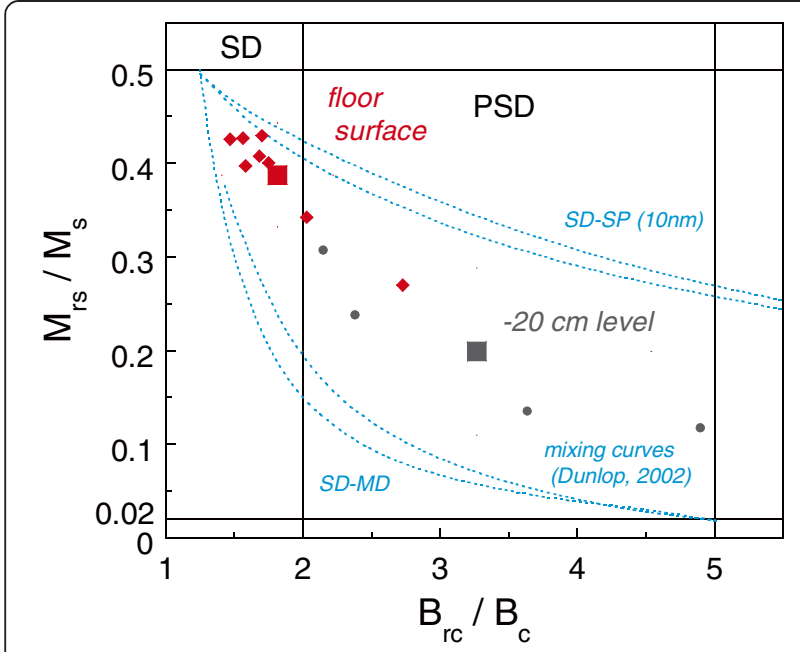

Figure 4 Measured hysteresis parameters shown on a Day plot. Red diamonds (gray circles) indicate data points for samples from floor surface $(-20-\mathrm{cm}$ level). The red (gray) square represents the averaged parameter for samples from floor surface $(-20-\mathrm{cm}$ level) with their one standard deviation. Threshold values for single domain (SD), pseudo-single domain (PSD), and multi-domain (MD) regions are adopted from Dunlop (2002). Dotted curves are theoretical mixing curves for SD-MD and SD-SP (super paramagnetic) magnetite grains adapted also from Dunlop (2002).

from the hysteresis measurements and the thermomagnetic curve measurements.

\section{Tsunakawa-Shaw paleointensity experiments}

Six successful results were obtained from the floor surface samples by the selection criteria. The representative one is illustrated in Figure 8a. The resultant archeointensities range between 43.2 and $49.6 \mu \mathrm{T}$, giving an average of $47.3 \mu \mathrm{T}$ with a standard deviation of $2.2 \mu \mathrm{T}$ (Table 1). This is fairly consistent with the in situ geomagnetic field at the time of the reconstruction $(46.4 \mu \mathrm{T})$. For the successful results, linear portions in the NRM-TRM1* diagrams are derived from the NRM fractions more than $50 \%$ of the total extrapolated NRMs $\left(f_{N} \geq 0.5\right)$ except one (sample 2). Degree of alterations in first laboratory heating is suggested to be small, namely at most approximately $7 \%$, based on the slopes estimated from the ARM0-ARM1 diagrams slope $_{\mathrm{A} 1}$, 0.932 to 1.04 , Table 1). Thus, the successful results seem to be of good quality.

Only one successful result was obtained from the $-20-\mathrm{cm}$ level samples by the selection criteria. It yielded an archeointensity of $31.6 \mu \mathrm{T}$ (Figure $8 \mathrm{~b}$ and Table 1), which is inconsistent with the in situ geomagnetic field of $46.4 \mu \mathrm{T}$. In this result, the archeointensity is estimated from $74 \%$ of the total extrapolated NRMs $\left(f_{N}=0.743\right)$ and degree of alteration in first laboratory heating is suggested to be negligible $\left(\right.$ slope $_{\mathrm{A} 1},=1.01$ ). Quality of this result seems to be also good in spite of the inconsistency.

On average, LTD demagnetized $21.4 \%$ and $10.0 \%$ of ARM0s for the floor surface and $-20-\mathrm{cm}$ level samples, respectively (Table 1 ). Because LTD treatment is known to be effective technique for selective removal of MD-like remanences in Ti-poor titanomagnetite (Ozima et al. 1964; Dunlop and Ozdemir 2007), it is considered that these samples certainly had such remanences but they are more or less removed.

About the remanence anisotropies of the samples, ratios of $\mathrm{ARM}_{\mathrm{TRM} \text { direction }}$ to $\mathrm{ARM}_{\mathrm{NRM} \text { direction }}$ resulted in 0.941 to 1.12 except for the sample 12 which showed the ratio as 1.24 (Table 1). These values seem to be typical of baked clays, for example, Kovacheva et al. (2009) reported that baked clay and soils collected from archeological sites in France and Bulgaria resulted in TRM anisotropy ratios less than 1.20 for about $80 \%$ of the collection.
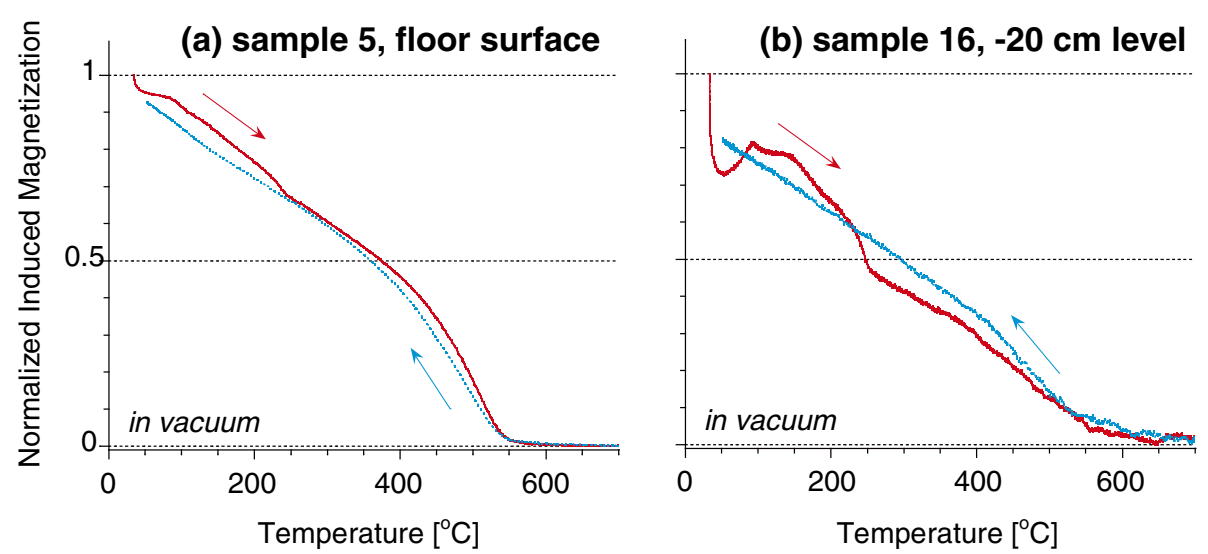

Figure 5 Representative thermomagnetic curves. The curves are shown for (a) sample 5 from floor surface and (b) sample 16 from -20-cm level. Heating (cooling) curves are indicated in red (blue). Some characteristic behaviors that appeared in the heating curves below approximately $100^{\circ} \mathrm{C}$ are artifact due to the instrument. 
(a) sample 5 , floor surface

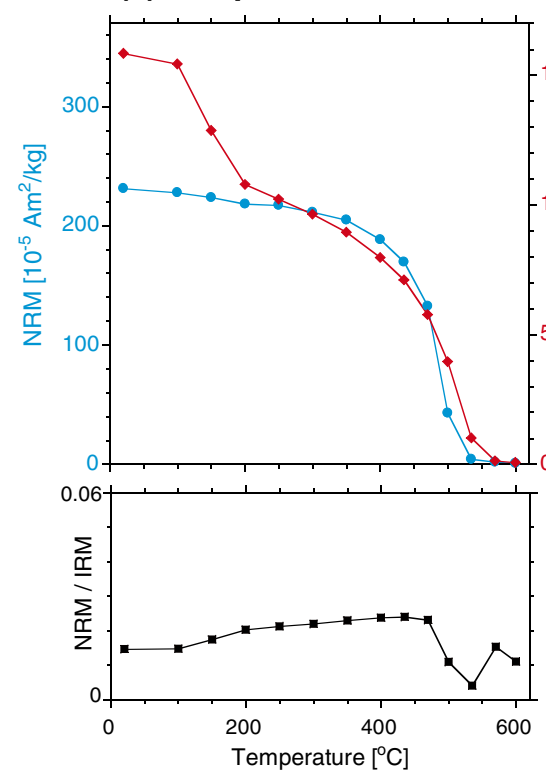

(b) sample $16,-20 \mathrm{~cm}$ level

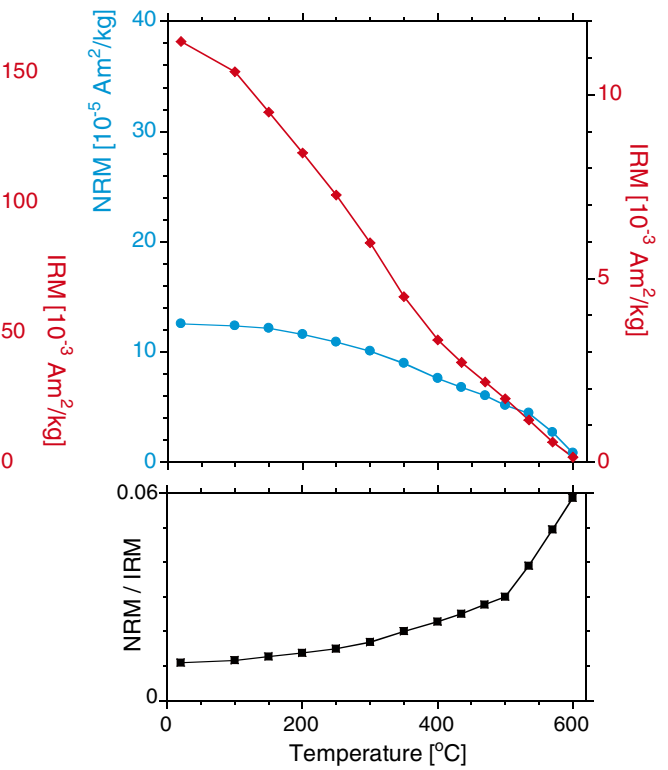

Figure 6 Thermal demagnetization results of NRM and IRM intensities. The curves are shown for (a) sample 5 from floor surface and (b) sample 16 from -20-cm level. Blue (red) curves indicate the demagnetization results for NRM (IRM). Black curves illustrate variations of NRM/IRM ratios.

(a) sample 5, floor surface
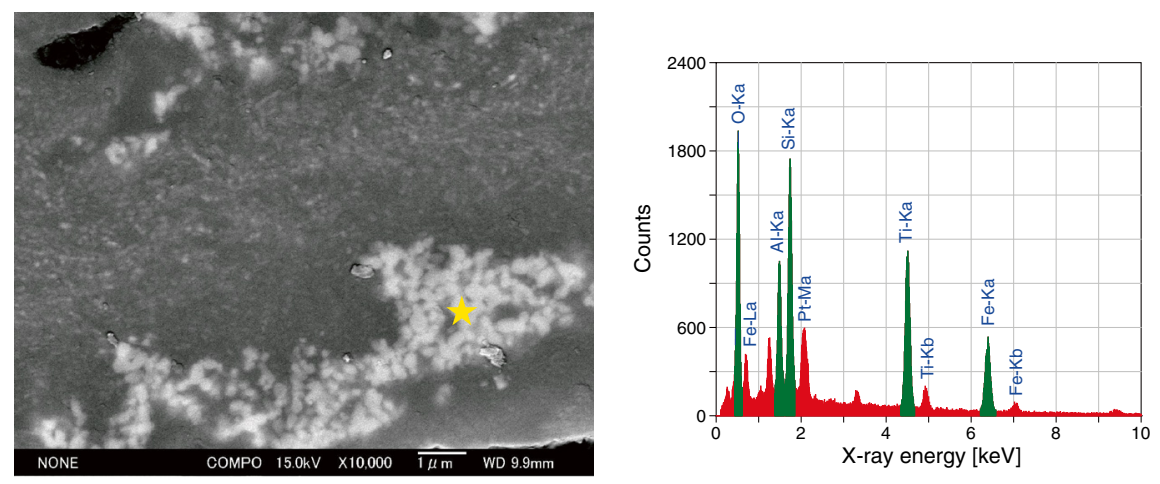

(b) sample 16, $-20 \mathrm{~cm}$ level
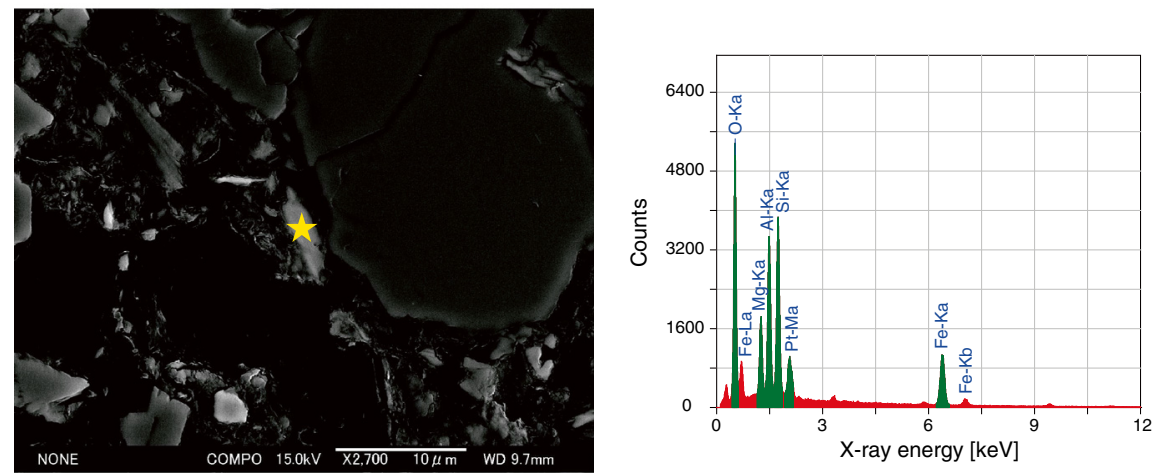

Figure 7 SEM observation results. The results are shown for (a) sample 5 from floor surface and (b) sample 16 from -20-cm level. Left images are back-scattered electron images. Right diagrams are results of the EDS point analyses made on the points indicated by yellow stars in the left images. 
(a) sample 5, floor surface
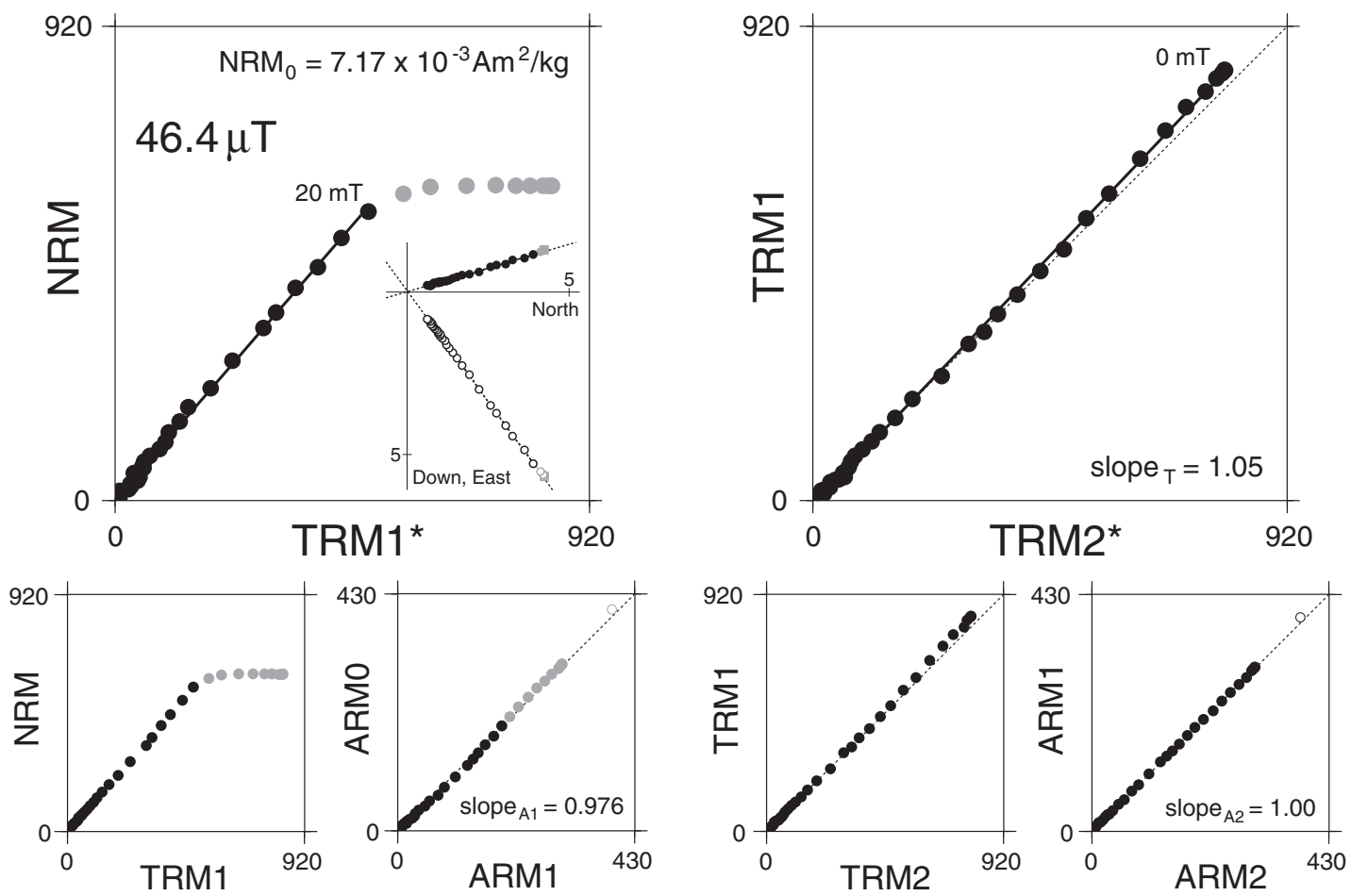

(b) sample 16, $-20 \mathrm{~cm}$ level
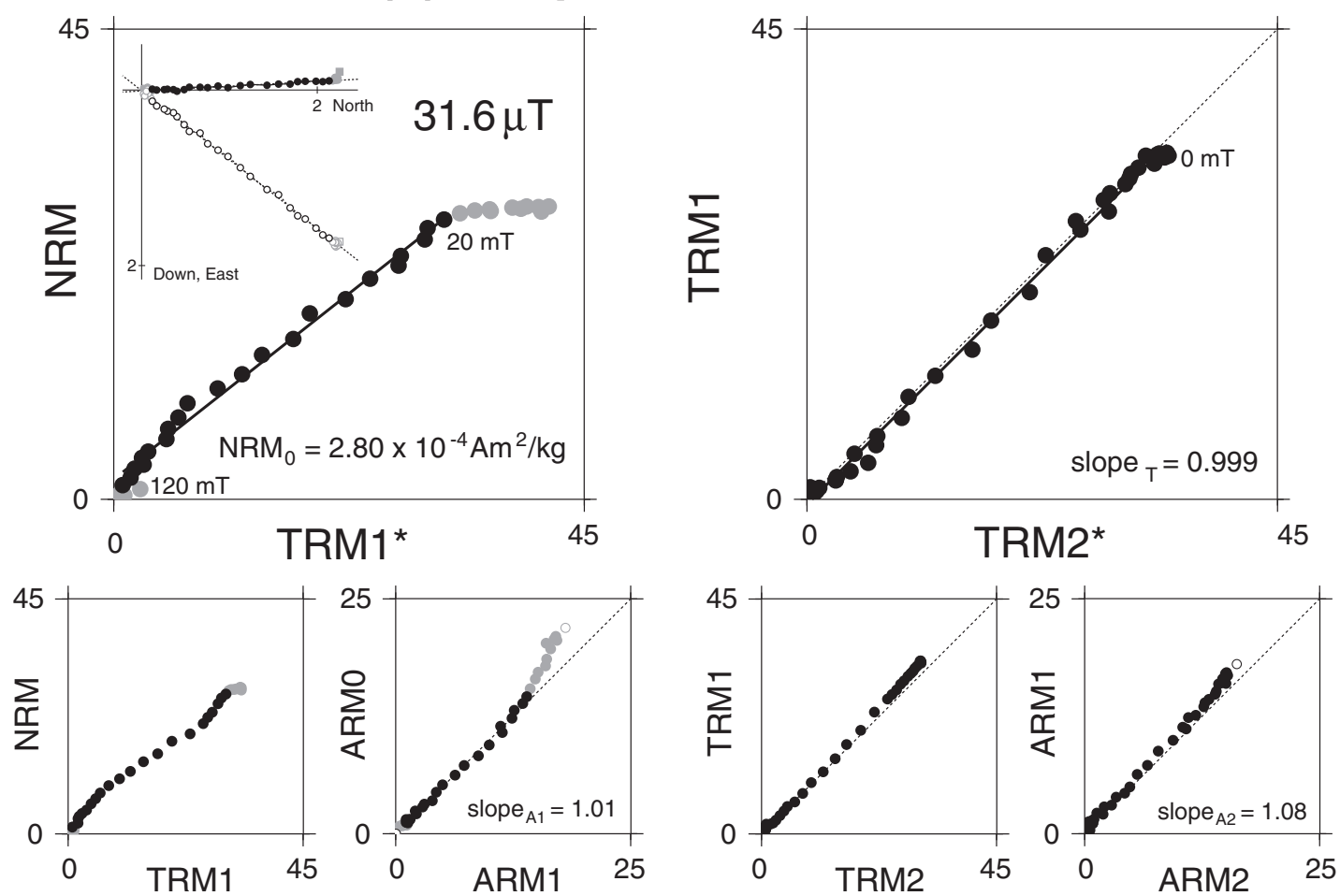

Figure 8 (See legend on next page.) 
(See figure on previous page.)

Figure $\mathbf{8}$ Representative successful results of the Tsunakawa-Shaw archeointensity (paleointensity) experiments. The results are shown for (a) sample 5 from floor surface and (b) sample 16 from $-20-\mathrm{cm}$ level. The left-hand (right-hand) side diagrams indicate results from the first (second) laboratory heating. Closed symbols correspond to coercivity intervals for the linear segments. Orthogonal vector-end-point diagrams for the AF demagnetization on NRM are also displayed as insets, where closed (open) symbols indicate projections onto horizontal (vertical) planes. Units are in $10^{-5} \mathrm{Am}^{2} / \mathrm{kg}$.

\section{Discussion}

Application of the Tsunakawa-Shaw method yielded the averaged archeointensity of $47.3 \mu \mathrm{T}$ with a standard deviation of $2.2 \mu \mathrm{T}(N=6)$ from the floor surface samples and the archeointensity of $31.6 \mu \mathrm{T}(N=1)$ from the $-20-\mathrm{cm}$ level samples (Figure 9 and Table 1). The former result is fairly consistent with the in situ geomagnetic field at the time of the reconstruction (46.4 $\mu \mathrm{T}$ ) while the latter one is significantly lower than the in situ field. This is probably because the floor surface samples acquired full TRMs as their NRMs during the firing of the reconstructed kiln whereas the $-20 \mathrm{~cm}$ level samples only acquired partial TRMs.

From the in situ temperature record during the firing (Figure 2), it is clear that the floor surface samples experienced high temperature of approximately $1,000^{\circ} \mathrm{C}$ while the -20 -cm level samples were only exposed at low temperature, at most approximately $350^{\circ} \mathrm{C}$. It is considered that the former samples were baked well above the Curie temperature of magnetite (approximately $580^{\circ} \mathrm{C}$ ) resulting in acquisition of full TRMs, whereas the latter ones were below that temperature leading to acquisition of partial TRMs. The acquisition of full and partial TRMs for the former and latter samples are respectively implied from the results of the ThD experiments (Figure 6). In the Tsunakawa-Shaw experiment, we imparted full TRMs to the samples in laboratory and basically compared them with their NRMs. For the floor surface samples, NRMs are probably full TRMs and the comparison seem to result in the accurate archeointensities. In contrast, for the $-20-\mathrm{cm}$ level samples, NRMs are probably weak partial TRMs and thus the comparison would probably result in the weak paleointensity.

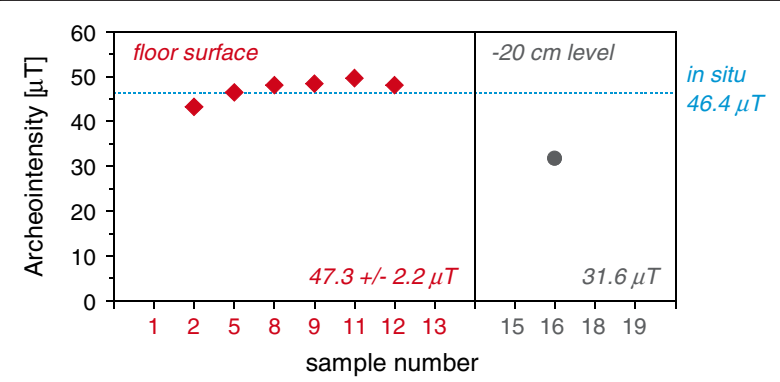

Figure 9 Summary of the archeointensity results obtained by the Tsunakawa-Shaw method.
Difference in the 'baking' temperatures between the floor surface samples and the -20 -cm level samples would probably also cause the differences in the rock magnetic characters. In the former samples, there are much more SD and/or SP titanomagnetite grains compared with the latter samples, and the former samples have high remanence intensities (e.g., ARM0s). From the view of the rock magnetic properties, the floor surface samples seem to be much more preferable for highfidelity archeointensity researches.

Importance of the anisotropy correction has been emphasized for accurate archeointensity determinations (e.g., Aitken et al. 1981). The Tsunakawa-Shaw method employs a built-in anisotropy correction using ARMs: ARM0, ARM1, and ARM2 are imparted with their directions approximately parallel to the NRM, TRM1, and TRM2 directions, respectively, and measured along with the stepwise AF demagnetizations; ratios of ARM0/ARM1 and ARM1/ARM2 are used to correct TRM1 and TRM2 into TRM1* and TRM2*, respectively. The floor surface samples yielded the successful archeointensity results fairy consistent with the in situ geomagnetic field, and thus the built-in correction seemed to work well. The degree of the correction is suggested to be $6 \%$ to $12 \%$ except for sample 12 considering the ratios of $\mathrm{ARM}_{\mathrm{TRM}}$ direction to $\mathrm{ARM}_{\mathrm{NRM}}$ direction (Table 1).

Necessity of the cooling rate correction has also been emphasized in many studies because the difference in that rate could result in biased archeointensity estimates (e.g., Mitra et al. 2013; Cai et al. 2014). For example, Usui (2013) reported that the cooling rate effect resulted in a $37 \%$ to $46 \%$ overestimated paleointensity for an oceanic gabbro, although it is not the case of the archeointensities. In the present study, there is large difference in the cooling rates between the kiln NRMs (approximately $24 \mathrm{~h}$ ) and the laboratory TRMs (approximately $2 \mathrm{~h}$ ). However, without such corrections, we obtained the archeointensity results fairy consistent with the in situ geomagnetic field from the floor surface samples. This suggests that the cooling rate correction is dispensable for the Tsunakawa-Shaw method, at least for a baked clay. It is noted that the main magnetic carriers of the floor surface samples might be Ti-poor titanomagnetites in fine PSD sizes, rather than in approximately 10 nm size: Yu (2011) experimentally demonstrated that the cooling rate effect was negligible for a $1.06 \mu \mathrm{m}$ PSD magnetite. 


\section{Conclusions}

Application of the Tsunakawa-Shaw method to the baked clay samples taken from a reconstructed kiln shows that the samples from floor surface provide the accurate archeointensity results. They are obtained with a built-in anisotropy correction using ARM and without any cooling rate corrections. A suite of the rock magnetic experiments and the SEM observations elucidate that dominant magnetic carriers of the floor surface samples are Ti-poor titanomagnetite grains in approximately $10 \mathrm{~nm}$ size, with SD and/or SP states. For archeointensity researches, baked clay samples from a kiln floor are considered to be ideal materials.

\section{Competing interests}

The authors declare that they have no competing interests.

\section{Authors' contributions}

MT and NN conducted the reconstruction experiment and collected the samples. YY carried out the paleomagnetic and rock-magnetic measurements. All contributed to the discussion, and YY wrote the manuscript. All authors read and approved the manuscript.

\section{Acknowledgements}

We thank Tadashi Nakajima and Katsumi Yaskawa for the reconstruction experiment, Kimio Hirooka and Hiroshi Nakamura for long-term storage of the samples, and Yukako Nabeshima for help with the measurements. Constructive comments by Yongjae Yu and Hidetoshi Shibuya improved the manuscript. This study was partly supported by JSPS KAKENHI Grant Numbers 21500991, 23740340, and 25247073 and by the Kochi University Research Project 'Research Center for Global Environmental Change by Earth Drilling Sciences.'

\section{Author details}

${ }^{1}$ Center for Advanced Marine Core Research, Kochi University, B200 Monobe, Nankoku, Kochi 783-8502, Japan. ${ }^{2}$ Okayama University of Science, 1-1 Ridaicho Kita Ward, Okayama 700-0005, Japan. ${ }^{3}$ Natsuhara Giken Co. Ltd., 1-13-24 Niitaka, Yodogawa, Osaka 532-0033, Japan.

Received: 16 January 2015 Accepted: 14 April 2015

Published online: 08 May 2015

\section{References}

Aitken MJ, Alcock P, Bussell GD, Shaw C (1981) Archaeomagnetic determination of the past geomagnetic intensity using ancient ceramics: allowance for anisotropy. Archaeometry 23:53-64

Cai S, Tauxe L, Deng C, Pan Y, Jin G, Zheng J, Xie F, Qin H, Zhu R (2014) Geomagnetic intensity variations for the past $8 \mathrm{kyr}$ : new archaeointensity results from Eastern China. Earth Planet Sci Lett 392:217-229

Coe RS, Gromme S, Mankinen EA (1978) Geomagnetic paleointensities from radiocarbon-dated lava flows on Hawaii and the question of the Pacific nondipole low. J Geophys Res 83(B4):1740-1756

Day R, Fuller M, Schmidt VA (1977) Hysteresis properties of titanomagnetites: grain size and compositional dependence. Phys Earth Planet Inter 13:260-267

Domen $\mathrm{H}$ (1977) A single heating method of paleomagnetic field intensity determination applied to old roof tiles and rocks. Phys Earth Planet Inter 13:315-318

Donadini F, Korte M, Constable CG (2009) Geomagnetic field for 0-3 ka: 1. New data sets for global modeling. Geochem Geophys Geosyst 10, Q06007, doi:10.1029/2008GC002295

Donadini F, Korhonen K, Riisager P, Pesonen L (2006) Database for Holocene geomagnetic intensity information. EOS Transac Am Geophysic Union 87(14):137

Dunlop DJ (2002) Theory and application of the Day plot (Mrs/Ms versus Hcr/Hc) 1 Theoretical curves and tests using titanomagnetite data. J Geophys Res 107:2056, doi:10.1029/2001JB000486

Dunlop D, Ozdemir O (2007) Magnetizations in rocks and minerals. In: Kono M. (ed) Treatise on Geophysics, vol. 5, Elsevier B.V., Amsterdam.
Genevey A, Gallet Y, Constable CG, Korte M, Hulot G (2008) Archeolnt: an upgraded compilation of geomagnetic field intensity data for the past ten millennia and its application to the recovery of the past dipole moment. Geochem Geophys Geosyst 9:Q04038, doi:10.1029/2007GC001881

Hirooka K (1971) Archaeomagnetic study for the past 2,000 years in Southwest Japan. Memoirs of the Faculty of Science, Kyoto University. Series Geology Mineralogy 38:167-207

Hong H, Yu Y, Lee CH, Kim RH, Park J, Doh S-J, Kim W, Sung H (2013) Globally strong geomagnetic field intensity circa 3000 years ago. Earth Planet. Sci Lett 383:142-152

International Association of Geomagnetism and Aeronomy, Working Group V-MOD (2010) International Geomagnetic Reference Field: the eleventh generation. Geophys J Int 183:1216-1230

Kitazawa K (1970) Intensity of the geomagnetic field in Japan for the past 10,000 years. J Geophys Res 75:7403-7411

Korhonen K., Donadini F, Riisager P, and Pesonen L (2008) GEOMAGIA50: an archeointensity database with PHP and MySQL: Geochem Geophys Geosyst: 9, doi:10.1029/2007GC001, 893.

Kono M (1978) Reliability of palaeointensity methods using alternating field demagnetization and anhysteretic remanences. Geophys J R Astron Soc 54:241-261

Kovacheva M, Chauvin A, Jordanova N, Lanos P, Karloukovski V (2009) Remanence anisotropy effect on the palaeointensity results obtained from various archaeological materials, excluding pottery. Earth Planets Space 61:711-732

Mitra R, Tauxe L, Mclntosh SK (2013) Two thousand years of archeointensity from West Africa. Earth Planet Sci Lett 364:123-133

Mochizuki N, Tsunakawa H, Oishi Y, Wakai S, Wakabayashi K, Yamamoto Y (2004) Palaeointensity study of the Oshima 1986 lava in Japan: implications for the reliability of the Thellier and LTD-DHT Shaw methods. Phys Earth Planet Inter 146:395-416

Mochizuki N, Maruuchi T, Yamamoto Y, Shibuya H (2013) Multi-level consistency tests in paleointensity determinations from the welded tuffs of the Aso pyroclastic-flow deposits. Phys Earth Planet Inter 223:40-54

Nagata T, Arai Y (1963) Secular variation of the geomagnetic total force during the last 5,000 years. J Geophys Res 68:5277-5281

Nakajima T, Torii M, Natsuhara N, Yaskawa K, Takagi M, Ikeguchi K, Kawai N (1974) Remanent magnetism of the reconstructed ancient kiln. Rock Magnetism Paleogeophy 2:28-31

Oishi Y, Tsunakawa H, Mochizuki N, Yamamoto Y, Wakabayashi K, Shibuya H (2005) Validity of the LTD-DHT Shaw and Thellier palaeointensity methods: a case study of the Kilauea 1970 lava. Phys Earth Planet Inter 149:243-257

Ozima M, Ozima M, Akimoto S (1964) Low temperature characteristics of remanent magnetization of magnetite - self-reversal and recovery phenomena of remanent magnetization. J Geomag Geoelectr 16:165-177

Rolph TC, Shaw J (1985) A new method of paleofield magnitude correction for thermally altered samples and its application to Lower Carboniferous lavas. Geophys J R Astron Soc 80:773-781

Sakai H, Hirooka K (1986) Archaeointensity determinations from Western Japan. J Geomagn Geoelectr 38:1323-1329

Sasajima S, Maenaka K (1966) Intensity studies of the Archaeo-secular variation in west Japan, with special reference to the hypothesis of the dipole axis rotation. Mem Coll Science Kyoto Univ 33:53-67

Shibuya H (1980) Geomagnetic secular variation in Southwest Japan for the past 2,000 years by means of archaeomagnetism. M. E. Thesis, Faculty of Engineering Science, Osaka Univ., p 54

Takai A, Shibuya H, Yoshihara A, Hamano Y (2002) Paleointensity measurements of pyroclastic flow deposits co-born with widespread tephras in Kyushu Island, Japan. Phys Earth Planet Inter 133:159-179

Tanaka H (1979) Three paleointensities in the Holocene obtained from the lava flows in Oshima Island. Rock Magnetism Paleogeophy 6:25-26

Tanaka H (1980) Paleointensities of the geomagnetic field determined from recent four lava flows of Sakurajima volcano, West Japan. J Geomagn Geoelectr 32:171-179

Tsunakawa H, Shaw J (1994) The Shaw method of paleointensity determinations and its application to recent volcanic rocks. Geophys J Int 118:781-787

Usui Y (2013) Paleointensity estimates from oceanic gabbros: effects of hydrothermal alteration and cooling rate. Earth Planets Space 65:985-996, doi:10.5047/eps.2013.03.015

Yamamoto Y, Hoshi H (2008) Paleomagnetic and rock magnetic studies of the Sakurajima 1914 and 1946 andesitic lavas from Japan: a comparison of the LTD-DHT Shaw and Thellier paleointensity methods. Phys Earth Planet Inter $167: 118-143$ 
Yamamoto Y, Tsunakawa H (2005) Geomagnetic field intensity during the last 5 Myr: LTD-DHT Shaw palaeointensities from volcanic rocks of the Society islands, French Polynesia. Geophys J Int 162:79-114

Yamamoto Y, Tsunakawa H, Shibuya H (2003) Paleointensity study of the Hawaiian 1960 lava: implications for possible causes of erroneously high intensities. Geophys J Int 153:263-276

Yamamoto Y, Shibuya H, Tanaka H, Hoshizumi H (2010) Geomagnetic paleointensity deduced for the last 300 kyr from Unzen Volcano, Japan, and the dipolar nature of the Iceland Basin excursion. Earth Planet Sci Lett 293:236-249

Yamazaki T, Yamamoto Y (2014) Paleointensity of the geomagnetic field in the Late Cretaceous and earliest Paleogene obtained from drill cores of the Louisville seamount trail. Geochem Geophys Geosyst: 15. doi:10.1002/ 2014GC005298

Yoshihara A, Kondo A, Ohno M, Hamano Y (2003) Secular variation of the geomagnetic field intensity during the past 2000 years in Japan. Earth Planet Sci Lett 210:219-231

Yu Y (2011) Importance of cooling rate dependence of thermoremanence in paleointensity determination. J Geophys Res 116:B09101, doi:10.1029/ 2011 JB008388

Yu Y, Doh SJ, Kim W, Park YH, Lee HJ, Yim Y, Cho SG, Oh YS, Lee DS, Lee HH, Gong MG, Hyun DH, Cho JK, Sin YS, Do MS (2010) Archeomagnetic secular variation from Korea: implication for the occurrence of global archeomagnetic jerks. Earth Planet Sci Lett 294:173-181

\section{Submit your manuscript to a SpringerOpen ${ }^{\circ}$} journal and benefit from:

- Convenient online submission

- Rigorous peer review

- Immediate publication on acceptance

- Open access: articles freely available online

- High visibility within the field

- Retaining the copyright to your article

Submit your next manuscript at $>$ springeropen.com 